\title{
Biomoléculas en nanotecnología
}

\author{
Biomolecules in nanotechnology
}

\author{
José A. D. L. C. Rodríguez Galván
}

Instituto de Ciencias Nucleares, Universidad Nacional Autónoma de México, Circuito Exterior C.U., 045 I0 México D.F., México. Autor para correspondencia: andres.rodriguez@nucleares.unam.mx

Artículo recibido el 2 de febrero de 20 II.Aprobado, tras revisión el 17 de mayo de $201 \mathrm{I}$.

\section{Resumen}

Las propiedades de reconocimiento molecular y autoensamble intrínseco de las biomoléculas han fascinado a la nanotecnología. Su incursión está revolucionando la forma de fabricar nanomateriales. En este trabajo revisamos un número de publicaciones que emplean biomoléculas en la fabricación de Nanomateriales.

Palabras clave: nanotecnología, biomoléculas, nanomateriales.

\begin{abstract}
Molecular recognition and intrinsic self-assembly of biomolecules are the properties that have fascinated nanotechnology. The technology involved in the elaboration of nanomaterial revolutionized when those properties were explored. In the present work, we review a set of selected publications referring to the use of biomolecules in nanomaterials fabrication.
\end{abstract}

Keywords: nanotechnology, biomolecules, nanomaterials. 


\section{Introducción}

Todos los organismos vivos como hongos, plantas, insectos y animales, por mencionar algunos de ellos, comparten en común las mismas unidades estructurales; células y la misma clase de componentes celulares; biomoléculas como DNA, RNA y proteínas, las cuales son construidas por unidades monoméricas como nucleótidos y aminoácidos. Además de utilizar rutas similares en la síntesis de sus componentes celulares, los organismos vivos comparten la misma forma de almacenar información y derivan de la evolución de un ancestro en común. La naturaleza a través de la evolución molecular seleccionó a las biomoléculas a manera de ladrillos para obtener estructura y función en los diferentes niveles de organización. Esos principios básicos de ingeniería han sido estudiados los últimos 200 años. A pesar de que el conocimiento que se tiene no es completo ha sido el suficiente para incitar cambios en nanociencia y nanotecnología. Por ejemplo, las biomoléculas, así como algunos conceptos de la lógica de la vida, han sido adoptados por la nanociencia. Las biomoléculas y el concepto de autoensamble resultaron clave en la concepción de la forma de construcción "de abajo hacia arriba".

En la nanociencia existía anteriormente solo una forma de construcción "de arriba hacia abajo" en la cual la manipulación microscópica de un número pequeño de átomos o moléculas permitía formar patrones bien definidos en una escala inferior a los $100 \mathrm{~nm}$. En esta estrategia puede incluirse la litografía. Con la incorporación de las biomoléculas y en particular del concepto de autoensamble se generó una revolución en la nanociencia ya que surgió la forma de construcción "de abajo hacia arriba". La cual surge de la idea de que si las biomoléculas por sus propiedades de reconocimiento molecular pueden formar desde sistemas de almacenamiento de información (DNA) hasta complejas máquinas moleculares (ribosomas), la nanociencia podría imitar esa estrategia para construir sistemas con propiedades específicas (Seeman, 2003). La bionanotecnología actualmente emplea la forma de construcción hacia arriba ya que ha resultado un método potente y altamente eficaz para la creación espontánea y programada de arreglos y estructuras complejas a escala nanométrica (que pueden expandirse a una macro escala) a partir de biomoléculas (DNA, RNA y proteínas) y sus unidades monoméricas (nucleótidos y aminoácidos; Zhang, 2003).

¿Cuál es el propósito de construir arreglos y nanoestructuras con una geometría deseada? Uno de los principales objetivos es emplear los arreglos y nanoestructuras para organizar otras moléculas, sean orgánicas o inorgánicas, de una forma programada. Por ejemplo, usando enrejados de DNA como plataformas para anclar y organizar macromoléculas biológicas, los cuales en su organización serán semejantes a la estructura presente en un cristal, lo que permite determinar la estructura tridimensional de las macromoléculas por cristalografía de rayos $X$. Otro objetivo es construir componentes e integrarlos en nanocircuitos electrónicos para fabricar la siguiente generación de dispositivos electrónicos, por ejemplo, se ha usado DNA de doble hélice como plantillas para organizar nanopartículas metálicas, que se plantean como un precursor para arreglos de nanoalambres (Seeman, 2003).

El papel de los biomateriales en nanotecnología es muy amplio y dinámico, es imposible cubrir el espectro completo, por tanto este trabajo se enfoca en dar una introducción al autoensamble molecular, además de una breve revisión de algunos trabajos que han usado biomoléculas como base para fabricación de algunos materiales. Para la revisión clasificamos las biomoléculas en dos grupos: nativos y sintéticos, a los primeros les denominamos nativos debido a que su estructura tridimensional es el resultado de la evolución molecular. A los segundos les llamamos sintéticos porque su estructura tridimensional resulta del conocimiento que tiene el hombre en diversas áreas como biología, biotecnología, química y cómputo. La clasificación es únicamente con la finalidad de introducirnos en este campo emergente ya que existe una gran variedad de bionanomateriales que actualmente se han sintetizado.

\section{Autoensamble molecular}

El autoensamble molecular es ubicuo en la naturaleza: celdas unitarias en cristales y minerales, formación de conchas y dientes, aceite formando gotas en agua, fibras de colágeno y la formación de numerosas máquinas moleculares complejas tales como ribosomas, virus y fotosistemas cultivadores de luz (Zhao y Zhang, 2006). El autoensamble es por definición la organización espontánea de moléculas en arreglos estructuralmente bien definidos y estables a través de interacciones no covalentes. Tales interacciones incluyen fuerzas electrostáticas, enlaces de hidrógeno, efecto hidrofóbico, puentes salinos y fuerzas de van der Waals (Zhang, 2003). En el autoensamble se reconocen dos elementos clave que son complementariedad química y estructural (Zhao y Zhang, 2006). Observando el proceso por el cual las estructuras biológicas son ensambladas en la naturaleza, los bionanotecnólogos han 


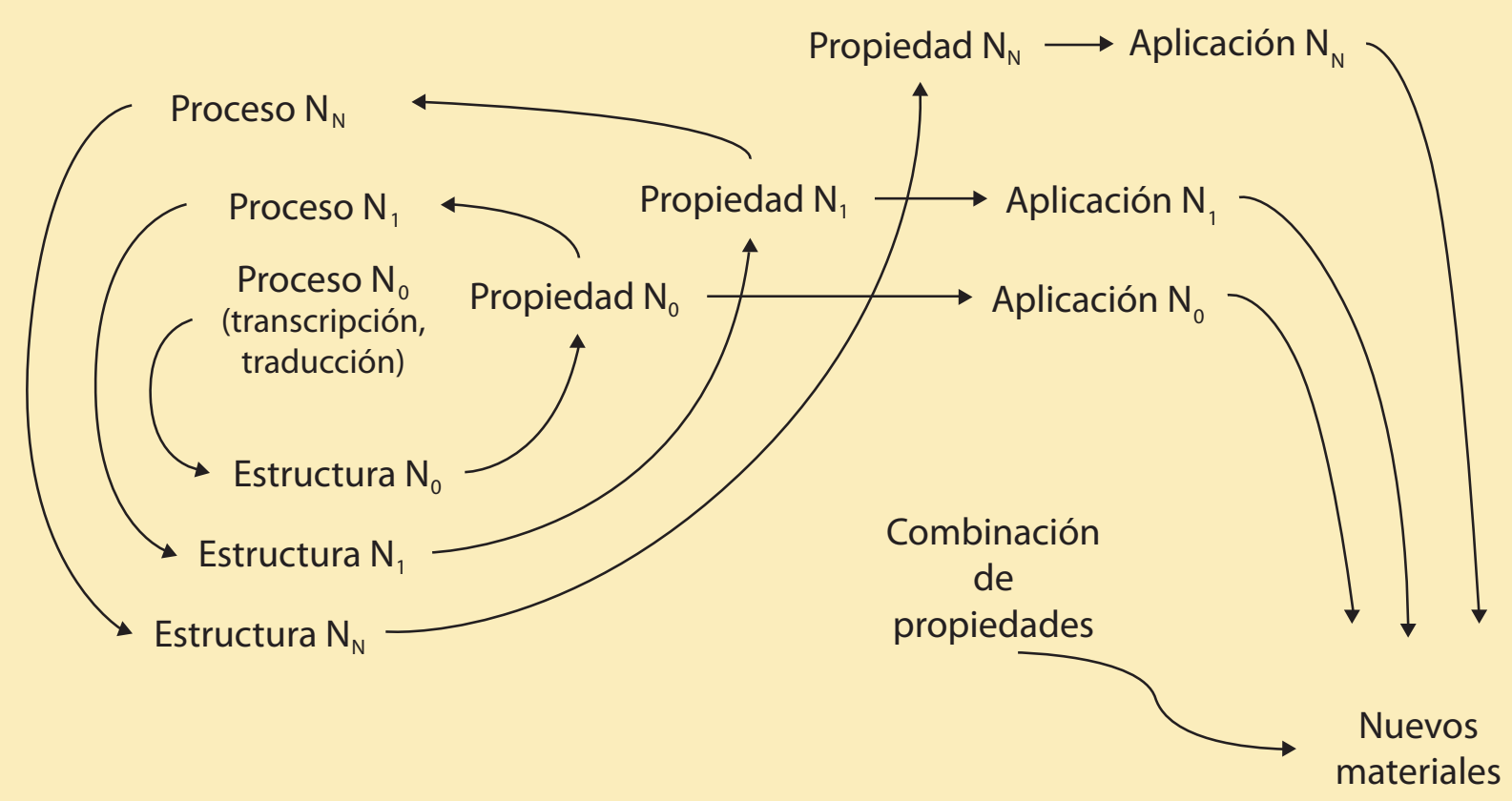

Figura 1. Niveles jerárquicos de biomoléculas y ensambles con aplicaciones en bionanotecnología.

comenzado a explotar el autoensamble como herramienta para la fabricación de nuevas nanoestructuras. Semejante a las estrategias de construcción que permitieron a los mayas construir maravillosas pirámides como la de KuKulKan uniendo solamente ladrillos, los bionanotecnólogos emplean ladrillos naturales como DNA, proteínas, nucleótidos y péptidos para construir nanoestructuras como nanotubos para depositar metales, nanovesículas para encapsular fármacos y nanofibras soporte para estimular el crecimiento de tejidos y minerales (Zhang, 2003).

Las biomoléculas resultan interesantes ya que además de sus propiedades de reconocimiento molecular intrínseco se caracterizan por ser robustas, tener adaptabilidad y multifuncionalidad. La robustez se puede definir como el grado de separación entre funcionalidad y fallo de una biomolécula, por ejemplo, algunas enzimas no dejan de ser funcionales, a pesar de tener algunas mutaciones que alteran su estructura terciaria, esta característica resulta de utilidad debido a que las biomoléculas al interactuar con materiales inorgánicos pueden sufrir cambios conformacionales. La adaptabilidad se refiere a la habilidad de una biomolécula para ajustarse a los cambios ambientales, modificando su arreglo estructural con la finalidad de ajustarse a las nuevas condiciones. Por último la multifuncionalidad se refiere a la habilidad de las biomo- léculas para proveer diferentes funciones tales como soporte mecánico y además de tener la habilidad de controlar algunos procesos bioquímicos, esta habilidad resulta de gran utilidad en la síntesis de nanoalambres metálicos (Buehler, 2009).

Todas las biomoléculas tienen propiedades realmente interesantes (ya que han sido optimizadas a través de millones de años) y su empleo en nanociencias no se restringe a un nivel de organización. En la Figura I, se busca representar esta idea. Se pueden emplear desde aminoácidos y nucleótidos hasta complejos moleculares como cápsides virales para sintetizar nuevos materiales. El ciclo inicia en el proceso $\left(\mathrm{N}_{0}\right)$, el cual se refiere únicamente a la síntesis (trascripción y traducción) que producirá una proteína con una estructura $\left(\mathrm{N}_{0}\right)$ que tendrá ciertas propiedades $\left(\mathrm{N}_{0}\right)$, las cuales pueden ser explotadas para algunas aplicaciones $\left(\mathrm{N}_{0}\right)$ en particular. Después si las propiedades de $\left(\mathrm{N}_{0}\right)$ le permiten escalar al siguiente nivel jerárquico $\left(N_{1}\right)$, en otras palabras si le permiten asociarse con proteínas semejantes o diferentes formarán la estructura $N_{\text {, }}$ que contendrá las propiedades $N_{1}$ y podrá emplearse en algunas aplicaciones $\mathrm{N}_{1}$. El ciclo continuará a través de diferentes niveles jerárquicos $N_{0}=0 \mathrm{a}$. La escala sería la única limitante en los niveles jerárquicos del biomaterial en una aplicación, pues en su definición la nanociencia plantea restricciones de escala. De igual 
forma existe la posibilidad de combinar diferentes propiedades (niveles) para generar materiales complejos, por ejemplo, un número de investigaciones han mostrado que se pueden fabricar fotosistemas complejos que captan fotones y los convierten directamente en electrones, empleando complejos fotosintéticos de plantas verdes y péptidos sintéticos como detergentes (Zhang, 2005).

\section{Aprovechando los materiales nativos}

Las biomoléculas que denominamos nativas ocurren en sistemas biológicos a través del autoensamble de moléculas cuya estructura es codificada por el genoma de un organismo, por ejemplo; actina, tubulina, colágeno, fibras amiloideas, DNA, proteínas globulares, cápsides de virus y fagos, entre otros. Esas biomoléculas solo requieren ser aisladas y purificadas para usarse en combinación con moléculas orgánicas o inorgánicas para fabricar nuevos materiales. En ocasiones la funcionalidad del material puede ser modificada a través de la expresión específica de secuencia de aminoácidos por ingeniería genética pero, en general, la arquitectura del material queda intacta en gran medida. De igual forma se pueden fabricar estructuras (esféricas, tubulares y anillos) expresando proteínas específicas, por ejemplo; la cápside icosaédrica de los rotavirus se compone de las proteínas VP2,VP6,VP7 y VP4, sin embargo, si se expresa la proteína VP6 únicamente, puede formar tubos o esferas con diámetros homogéneos (Rodríguez-Galván, 2008).

El uso de fibras, tubos y anillos autoensamblados de biomoléculas como plantillas para anclar y organizar nanopartículas semiconductoras, metálicas, magnéticas y cristales, para construir nanoalambres $y$ arreglos es de particular interés en la industria de electrónicos. Las plantillas suaves han acaparado fuertemente la atención ya que técnicas convencionales como la litografía se acercan a sus límites tanto teóricos como prácticos (McMillan, 2002). Esa aproximación para construir nanoalambres y arreglos puede arrojar dos productos, una vez que la plantilla orgánica ha sido removida un alambre / arreglo de partículas inmovilizadas en una superficie puede ser obtenido. Por otro lado, se ha demostrado algunos materiales híbridos, biomolécula-nanopartícula tienen nuevas propiedades, pues se combinan ambas, las de las nanopartículas y las de la plantilla biológica y esto provoca tengan respuestas totalmente diferentes ya sea a uno u otro material solo, lo cual incrementa su rango de aplicaciones (Tseng, 2006).
La proteína ferritina fue uno de las primeras biomoléculas que mostraron pueden ser explotadas para sintetizar nanopartículas inorgánicas (Masaki, 2009). Las ferritinas son una clase de proteínas que se encuentran en todos los dominios de la vida, su principal función es almacenar y secuestrar hierro. Éstas se componen de 24 monómeros que se ensamblan para formar una caja con $12 \mathrm{~nm}$ de diámetro externo y con una cavidad de $8 \mathrm{~nm}$ de diámetro interno en la cual óxido de hierro puede ser capturado ver Figura 2(a). La composición de aminoácidos en la superficie de la cavidad le permite anclar iones metálicos, los cuales formarán núcleos y partículas metálicas con un tamaño controlable por el diámetro interior de la caja. Siguiendo esta estrategia la proteína ferritina ha sido empleada para sintetizar partículas metálicas y magnéticas de óxido de cobalto, óxido de hierro y óxido de magnesio solo por mencionar algunos ejemplos, ver Figura 2(b). Por otro lado la proteína ferritina también se han empleado para decorar con partículas metálicas la superficie externa de carbono de capa simple (Whyburn, 2006).

De igual forma se han empleado plásmidos para anclar y organizar partículas metálicas. Un plásmido es una molécula de DNA circular extracromosomal capaz de replicarse independientemente en una bacteria huésped. Estas biomoléculas pueden ser sintetizadas en grandes cantidades y adoptar una variedad de topologías como: relajadas, enrolladas lineales y circulares (toroidal), dependiendo de algunas condiciones químicas, como: temperatura, $\mathrm{pH}$ y fuerza iónica. Recientemente la topología circular (toroidal) ha sido empleada para formar nanopartículas de diferentes metales en forma de discos, Figura 2(c y d). La metodología que siguieron es realmente interesante. En resumen: se incubaron los plásmidos con sales de cobalto, níquel y oro. Para formar las partículas la solución fue irradiada con luz UV. Con esta estrategia se logró sintetizar partículas con forma de discos de dimensiones que corresponden con el diámetro interno y altura de los plásmidos (Samson, 2009).

Uno de los primeros trabajos que mostraron autoensambles de proteínas pueden servir para organizar nanopartículas metálicas fue el realizado por Andrew Mcmillan y colaboradores en 2002, quienes emplearon una plantilla cristalina de proteínas genéticamente modificadas para organizar nanopartículas metálicas y semiconductoras preformadas (Qds). Ellos emplearon la proteína TF55B, la cual se ensambla espontáneamente en una estructura con forma de barril llamada chaperonina, esta proteína resultó muy interesante, porque puede autoensamblarse en arreglos cristalinos bidimensionales (2D). En primera instancia 
Ferritina

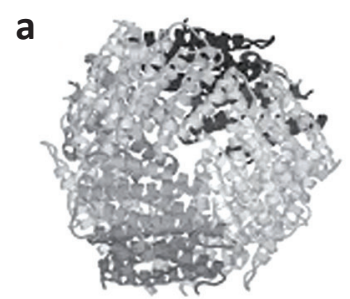

b

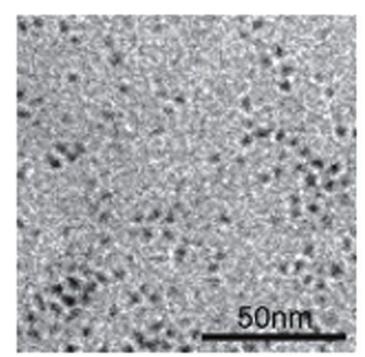

Plasmido

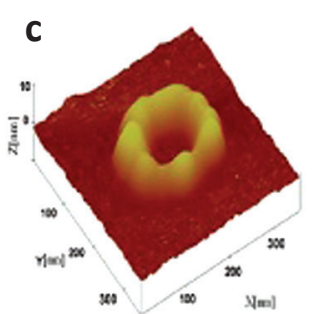

d

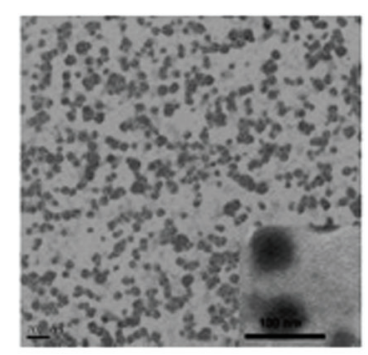

Chaperonina

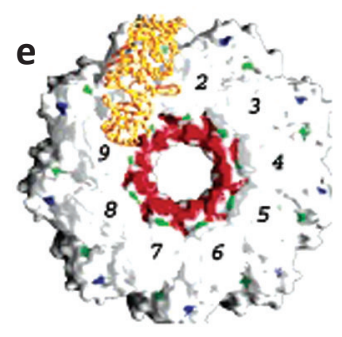

f

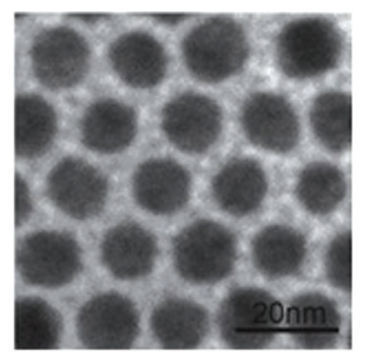

Virus M13

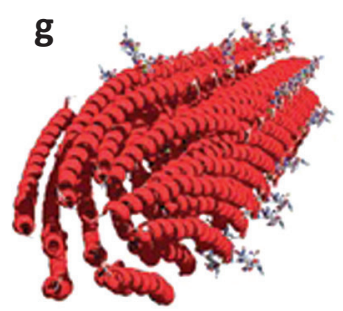

h

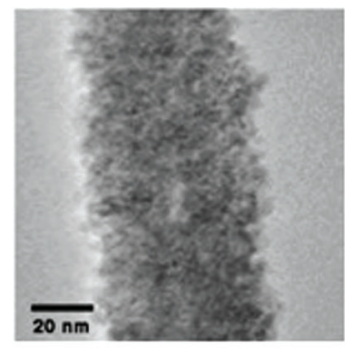

Figura 2. Biomateriales empleados en bionanotecnología, a,b) ferritina, c,d) plásmido, e,f) chaperona, y g,h) virus M13. Imágenes tomadas de Whyburn, 2008, Samson, 2009, McMillan, 2005, Nam, 2006 respectivamente.

Mcmillan y colaboradores modificaron genéticamente la proteína para incrementar su afinidad por partículas metálicas, esto lo lograron agregando residuos de cisteína que se proyectaban hacia el interior del barril y formaban una superficie rica en tioles, ver Figura 2(e). Después incubaban los barriles modificados con partículas metálicas de oro o zinc. Lo que encontraron es que en la cavidad de los barriles se anclaban las partículas metálicas y además podían formar arreglos de partículas metálicas bien definidos y de grandes extensiones, Figura 2(f). En trabajos posteriores reportaron que en los arreglos de chaperonina pueden nuclear y crecer partículas metálicas de níquel y cobalto. En general sus trabajos han demostrado que las proteínas pueden ayudar a generar arreglos de partículas metálicas los cuales son de gran valor para la industria de electrotécnicos (McMillan, 2002 y McMillan, 2005).

Diversos tubos o fibras se han explorado para formar nanoalambres, por ejemplo microtubulos, DNA, colágeno, cápsides virales, la región $\mathrm{N}$-terminal y región media de levadura (saccharomyces cerevisiae Sup35p). Por ejemplo Thomas Scheibel y colaboradores emplearon fibras amiloideas (fibras insolubles de proteína que son características de enfermedades neurodegenerativas) como plantillas para alienar na- nocristales de oro. Sin embargo las cápsides virales han mostrado una superioridad sobre otros sistemas (Whyburn, 2006). Por ejemplo, las cápsides del bacteriófago MI3 resultaron ideales como plantillas para organizar nanopartículas metálicas y magnéticas, además, su fácil modificación genética lo hace un sistema versátil para depositar cualquier clase de materiales orgánicos e inorgánicos. Actualmente con este sistema se ha dado un gran salto en el desarrollo de métodos de síntesis ambientalmente amigables, por ejemplo con el empleo de la luz ambiental como agente reductor se han podido fabricar nanoalambres de plata. Este método imita el proceso de biomineralización donde sistemas biológicos pueden sintetizar desde pequeñas estructuras de silicio hasta complejos ecosistemas como arrecifes coralinos. El equipo de la Dra. Ángela Belcher son el grupo punta en la síntesis de nanoalambres. Por ejemplo ellos han sintetizado nanoalambres de cobalto, oro y un híbrido oro-cobalto, Figura 2 (g, h). Ellos toman ventaja de aminoácidos que tienen una mayor afinidad por cobalto/oro y los expresan en las subunidades que forman la cápside del bacteriófago MI3, con esto incrementan la afinidad y la superficie efectiva donde se crecerán las partículas. La idea de expresar aminoácidos con una afinidad por materiales 
inorgánicos ha permitido anclar nanopartículas magnéticas, conductoras y semiconductoras a la superficie de biomoléculas, esta estrategia ha permitido formar una gran variedad de nanoalambres con un alto grado de organización (Yoo, 2006, Nam, 2006, Nam, 2008).

Desde hace 10 años el trabajo seminal de T. Douglas y colaboradores mostraron el virus del mosaico del tabaco podía ser empleado para anclar y organizar partículas metálicas (Masaki, 2007 y Evans, 2008). Actualmente la fabricación de nanoalambres es un área muy activa y cuenta con avances significativos, desafortunadamente, hay muchos obstáculos por atravesar para fabricar dispositivos electrónicos que utilicen los nanolambres. Por ejemplo, primero se requieren alambres homogéneos en sus propiedades electrónicas, además que sean monodispersos y además se debe contar con técnicas para ordenar los alambres en un arreglo deseado (circuitos electrónicos), por otro lado se debe contar con técnicas que permitan decorar las plantillas biológicas con combinaciones de diferentes partículas y se pueda tener un control sobre la relación.

\section{Diseñando materiales sintéticos}

La formación de biomoléculas sintéticas ocurre in vitro, a través del autoensamble de moléculas cuya estructura (secuencia) es diseñada y programada por el hombre. Explotando el autoensamble intrínseco de bases nitrogenadas y péptidos hoy en día se pueden construir estructuras sintéticas, este tipo de arquitecturas son resultado de la convergencia de la nanotecnología y biotecnología. Las estructuras se construyen programando la secuencia de los ladrillos, nucleótidos o aminoácidos. El DNA es una de las biomoléculas más prometedores para generar patrones y arquitecturas debido a su simplicidad (cuatro bases), su preciso reconocimiento molecular (A-T y G-C), gran ri-

a

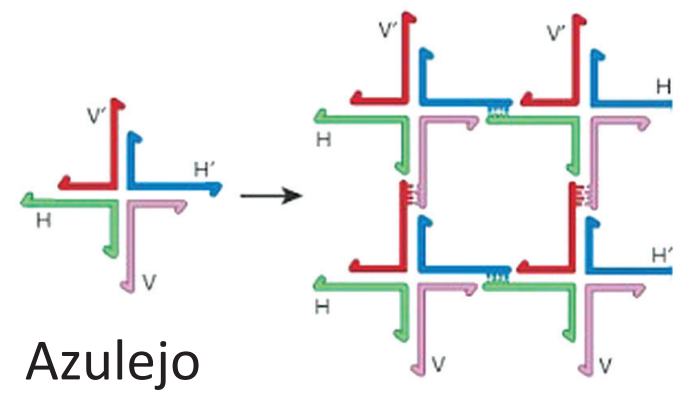

b

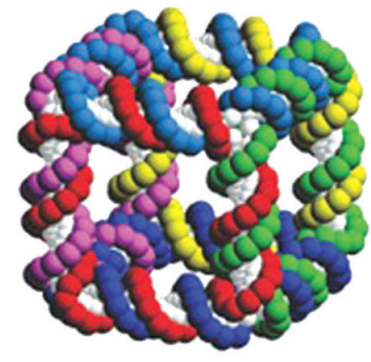

Cubo
C

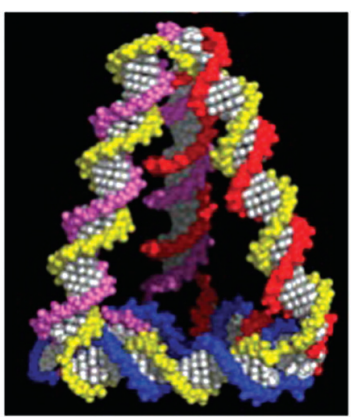

Tetraedro d

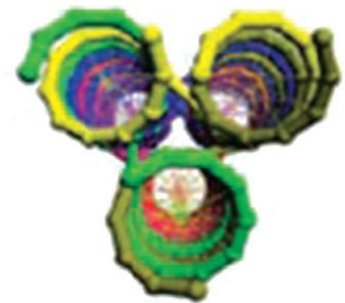

Tubos

Figura 3. Nanotecnología de DNA, (a) ensamblando azulejos, (b) se han podido generar estructuras como cubos, (c) tetraedros, y (d) tubulares. Imágenes tomadas de Seeman, 2003; Goodman, 2005 y Aldaye, 2008, respectivamente. 
gidez mecánica, una relativa estabilidad fisicoquímica, síntesis sencilla y económica (Goodman, 2005). El origen de esta aproximación data de inicios de los años setenta, cuando la manipulación genética permitió formar y unir moléculas de DNA con brazos adhesivos, comúnmente denominadas azulejos (Seeman, 2003). Un brazo adhesivo es una cadena sencilla que sobresale y sin aparear de un extremo de una doble hélice, que puede aparearse con un extremo complementario de otros azulejos de DNA y formar un complejo molecular ver Figura 3(a). De gran importancia resulta que los extremos son programables, lo cual ofrece un control predecible de las asociaciones intermoleculares y geometría en el punto de cohesión, además las bases otorgan una gran diversidad de combinaciones (Seeman, 2003). Algunas fascinantes nanoestructuras 2D/3D han sido creadas, por ejemplo enrejados 2D, y poliedros $2 \mathrm{D}$ y $3 \mathrm{D}$. Interesantes revisiones se han escrito sobre estas estructuras (Aldaye, 2008).

Por otro lado se han sintetizado tubos, cubos, octaedros y tetraedros empleando diferentes estrategias ver Figura 3. Por ejemplo; cadenas sencillas son ligadas y forman anillos que se interconectan para crear estructuras parecidas a un cubo, ver Figura 3(b). El cubo consiste de seis cadenas simples que se aparean para formar hélices dobles en cada eje, cada hélice forma una cara cuando se aparea con cuatro cadenas vecinas, por ejemplo, la cadena roja está unida a las cadenas verde, azul cielo, azul fuerte y rosa, e indirectamente unida a la amarilla, los bordes del cubo se forman por hélices dobles (Seeman, 2003). Recientemente se ha generado un tetraedro de síntesis extremadamente simple. El tetraedro consiste de triángulos rígidos de hélices de DNA, unidos de forma covalente en los vértices y bordes. Este se ensambla de cuatro cadenas cortas de DNA (Figura 4). Seis pares de dominios complementarios (se pueden identificar por los colores rojo, amarillo, azul, verde, negro y rosa) hibridan para formar los seis ejes de hélices dobles. En contraste a los métodos de síntesis de cubos y octaedros, la síntesis es sencilla. Las cuatro cadenas son combinadas en cantidades equimolares, la solución se calienta y enfría, después con enzimas se unen las cadenas en los grupos fosfato. Este método de producción tiene una eficiencia $\sim 95 \%$, mientras que en la estrategia que se empleó en la formación de cubos fue del $\sim 1 \%$, por lo cual hay una eficiencia superior en la estrategia del tetraedro (Goodman, 2005).

\section{Cadenas de DNA}
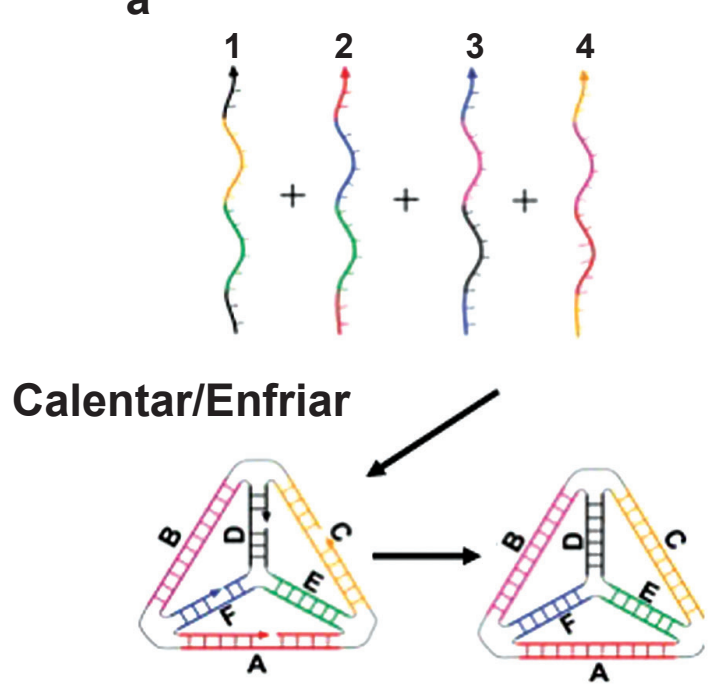

Unión de extremos b

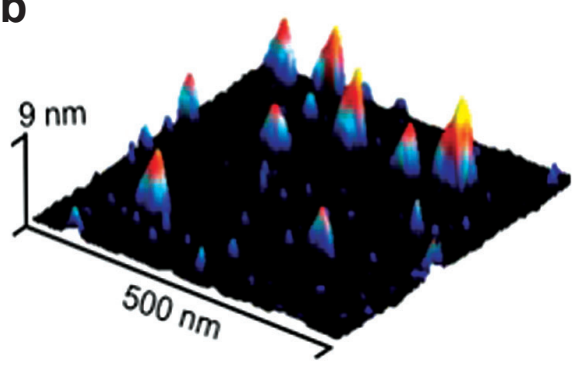

Figura 4. (a) Representación del diseño de un tetraedro de DNA. (b) Imágenes de topografía de los tetraedros por microscopía de fuerza atómica. Tomadas de Goodman, 2005. 
Además del DNA los péptidos son biomoléculas con un gran potencial en bionanotecnología. Los péptidos son secuencias de aminoácidos que consisten de dos o tres a cientos de aminoácidos unidos covalentemente. Resultan biomoléculas interesantes debido a su simplicidad, diversa funcionalidad y además son fáciles de designar y sintetizar (Fung, 2004). Actualmente el empleo de péptidos cortos (de 8 a 32 aminoácidos) ha permitido formar diversas arquitecturas. Se han diseñado diferentes motivos (Se denomina motivo a una secuencia particular de aminoácidos polares con carga positiva o negativa 0 no polares en un péptido) los cuales han permitido formar diferentes materiales, por ejemplo, fibras, tubos y esferas. Uno de los primeros péptidos en sintetizarse es el denominado "péptido lego" (Zhao y Zhang, 2006), ver Figura 5(a), el cual se ensambla por interacciones intermoleculares. La estructura es simple; se alternan varios aminoácidos para tener una cara hidrofílica y otra hidrofóbica, y en la cara hidrofílica se alternan aminoácidos con carga positiva o negativa. Se conocen diferentes formas de distribuir los aminoácidos cargados, a cada una se le denomina módulo, por ejemplo, módulo I, II, III, IV, etcétera, en el módulo uno la carga se distribuye alternando una carga negativa y una positiva, -+_-+_+-+; en el módulo
II la secuencia es --++--++; en el módulo III, ---+++,y módulo IV,----++++, de igual forma se pueden combinar los módulos. Si se colocan aminoácidos con cargas complementarias a las mostradas en los módulos, estos por complementaridad de carga podrán unirse, y controlando la interacción entre éstos se puede obtener diversos materiales: se han podido formar nanofibras que, a su vez se organizan y forman hidrogeles muy porosos con un alto contenido de agua, superior al $99,5 \%$, esos geles son muy parecidos a los de agarosa y otros hidrogeles (Zhao y Zhang, 2006). Uno de los motivos más interesantes tiene la estructura como un lípido, ver Figura 5(b), este tiene una cola hidrofóbica y una cabeza hidrofílica, por ejemplo, Vauthey y colaboradores (Fung, 2004) sintetizaron un péptido de siete y ocho aminoácidos con una cola hidrofóbica conteniendo alanina, valina o leucina, y una cabeza hidrofóbica con ácido aspártico, ellos encontraron que esos péptidos pueden ensamblarse en nanotubos y nanovesículas de diámetros homogéneos, de igual forma se han generado vesículas de múltiples capas cambiando los aminoácidos del motivo. Esos sistemas tienen el potencial para usarse como liberadores de genes y fármacos además de ayudar en el estudio de evolución molecular y en ingeniería de tejidos (Fung, 2004).
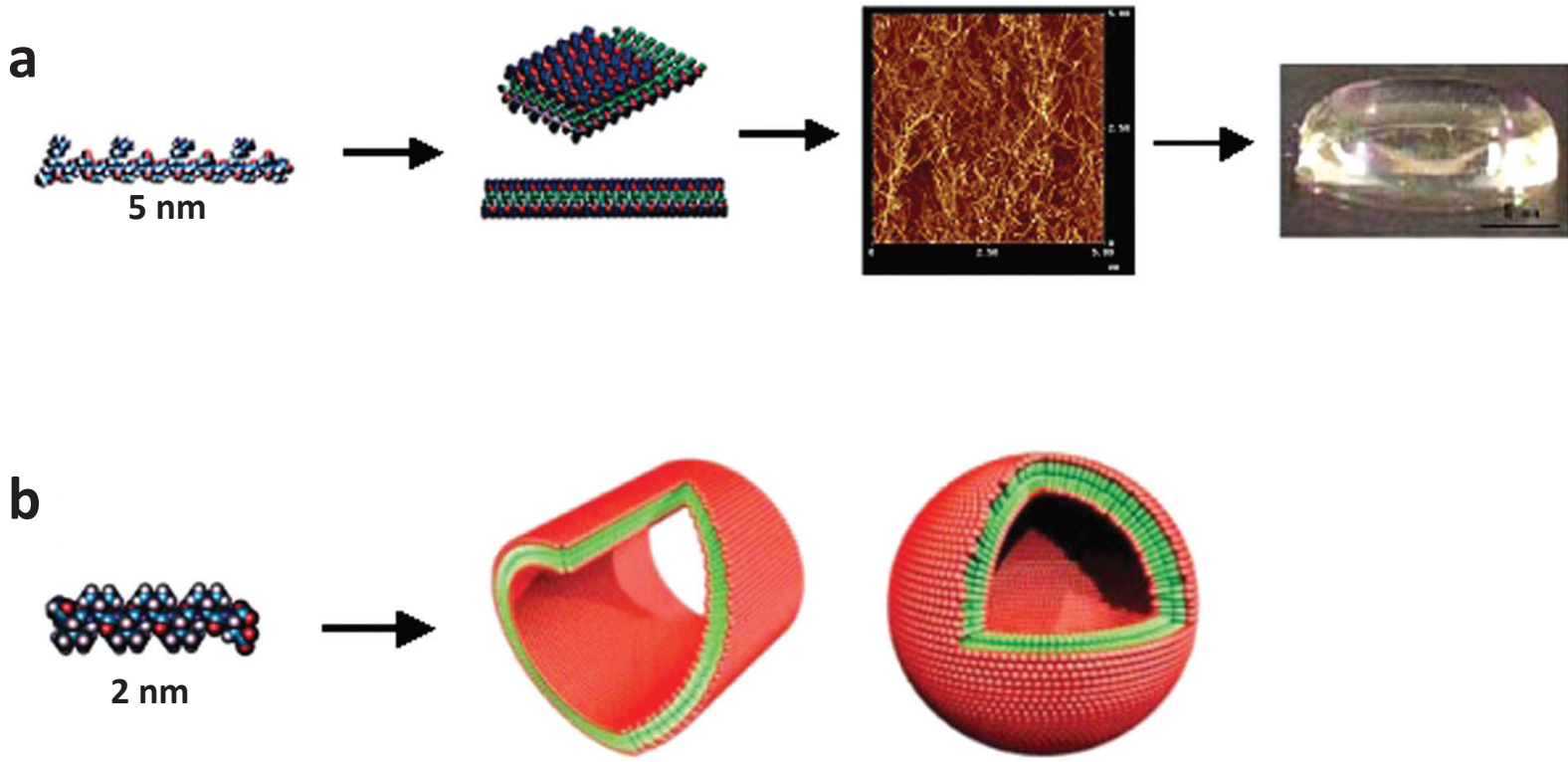

Figura 5. Motivos de péptidos, (a) péptido lego y (b) péptido como lípido. Imágenes tomadas de Zhang, 2003 y Zhao X. y Zhang S. 2006. 


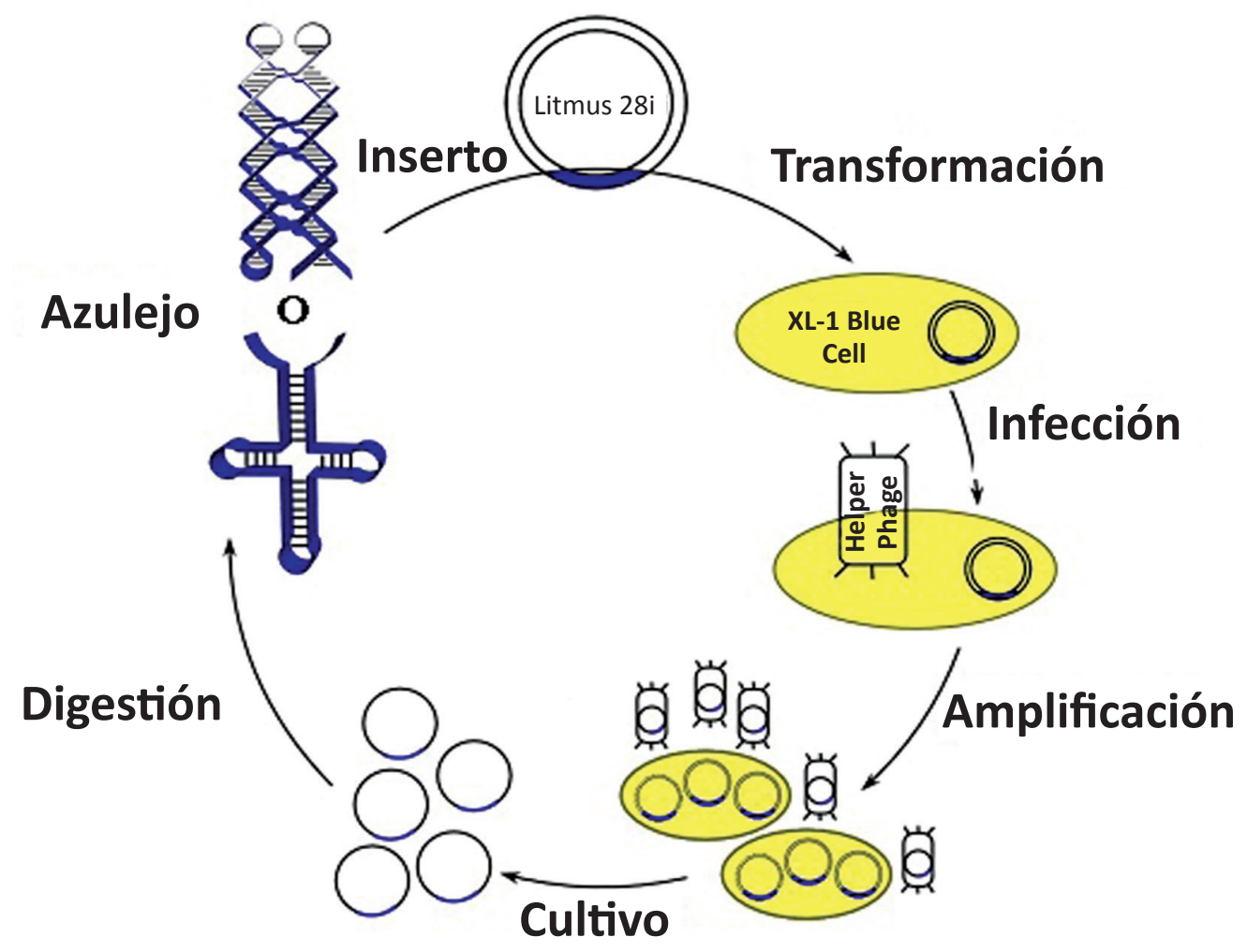

Figura 6. Esquema que muestra la replicación in Vivo de nanoestructuras de DNA. Imagen tomada de Lina, 2008.

\section{Replicando ensambles moleculares}

Resulta de gran importancia que los ensambles puedan ser replicados por métodos prácticos y económicos, pues su comercialización requerirá una producción a gran escala. En el caso de ensambles nativos, los avances en técnicas de DNA recombinante hacen posible escalar su producción. En el caso opuesto se encuentran algunos ensambles sintéticos, así como los de DNA (enrejados, cubos, tetraedros y azulejos) que se forman de la hibridación entre varias cadenas cortas sencillas, si se emplean estrategias convencionales, es decir expresión en bacterias y fagos, su ensamble no es posible ya que la DNA polimerasa sintetizaría complementos para todas las cadenas, llevando únicamente a la producción de hélices dobles (Seeman, 2003). Una opción es convertir las estructuras como cubos y tetraedros en largas cadenas simples. La cadena ahora podría ser sintetizada por la DNA polimerasa y después el producto se induciría a plegar en la forma original después de ser tratado por enzimas. De igual forma, se ha propuesto emplear plásmidos, por ejemplo los azulejos se insertan en un plásmido, bacterias de $E$. Coli son transformadas con el plásmido; después las bacterias son infectadas con un fago que ayuda en la amplificación del plásmido, por último se cosechan los plásmidos y son tratados con enzimas que ayudarán a extraer de la cadena del azulejo, la cual se plegará para formar el azulejo (Lina, 2008), ver Figura 6.

\section{Conclusión}

Los verdaderos avances en las nanociencias están apenas comenzando; los biomateriales, se ha demostrado, pueden revolucionar la ciencia de materiales y las nanociencias. Sin embargo, falta mucho por hacer para que en un futuro muy próximo veamos dispositivos electrónicos fabricados con materiales sintetizadas con ayuda de biomoléculas. Como Susan Lindquist dice, "cerca de 10.000 años atrás, los humanos comenzaron a domesticar plantas y animales, ahora es tiempo de domesticar moléculas". 


\section{Referencias}

Aldaye, Faisal A., Alison L. Palmer, Hanadi F. S. 2008. Assembling Materials with DNA as the Guide. Science. 32 I, I795-I799.

Buehler M. J. y Yung Y. C. 2009. Deformation and failure of protein materials in physiologically extreme conditions and disease. Nature Materials. 8, I75-188.

Evans, D.J. 2008. The bionanoscience of plant viruses: Templates and synthons for new materials. Journal of Materials Chemistry. 18 (32), 3746-3754.

Fung, S. Y., Hong, Y., Dhadwar, S. S., Zhao, X., Chen, P. 2004. Handbook of Nanostructured Biomaterials and Their Applications en Nanobiotechnology. Nalwa, H. S., Ed.; American Scientific Publishers: Stevenson Ranch, CA USA.

Goodman, R. P., Schaap, I.A.T.,Tardin, C. F. 2005. Rapid Chiral Assembly of Rigid DNA Building Blocks for Molecular Nanofabrication. Science. 310, 1661-1664.

Lina, C., Rinkera, S., Xing Wangb, Yan Liua, Nadrian C. Seeman, y Hao Y. 2008. In vivo cloning of artificial DNA nanostructures. PNAS. 105 (46), | 7626-|763I.

Lindquist, S. 2003. Presentation at the Third Multidisciplinary Workshop: Self-assembly of Peptides, Proteins in Biology Engineering and Medicine, Crete, Greece,August, I-5.

Masaki Uchida, Michael T. Klem, Mark Allen, Peter Suci, Michelle Flenniken, Eric Gillitzer, Zachary Varpness, Lars O. Liepold, Mark Young, y Trevor D. 2007. Biological Containers: Protein Cages as Multifunctional Nanoplatforms. Adv. Mater. 19, 1025-1042.

McMillan, R. A., Paavola, C. D., Howard, J., Chan, S. L., Zaluzec, N.J., Trent, J. D. 2002. Ordered nanoparticle arrays formed on engineered chaperonin protein templates. Nature Materials. I (4), 247-252.

McMillan, R.A., Howard, J., Zaluzec, N..., Kagawa, H.K., Mogul, R., Li, Y.-F., Paavola, C.D., Trent, J. D. A.
2005. self-assembling protein template for constrained synthesis and patterning of nanoparticle arrays. J. Am. Chem. Soc. I 27 (9), 2800-280 I.

Nam, K.T., Kim, D.-W.,Yoo, P..., Chiang, C.-Y., Meethong, N., Hammond, P.T., Chiang, Y.-M., Belcher, A.M. 2006. Virus-enabled synthesis and assembly of nanowires for lithium ion battery electrodes. Science. 3 I 2 (5775), 885-888.

Nam, K.T., Lee,Y.J., Krauland, E.M., Kottmann, S.T., Belcher, A.M. 2008. Peptide-mediated reduction of silver ions on engineered biological scaffolds. ACS Nano. 2 (7), | 480-| 486.

Rodríguez-Galván A., Heredia, A., Plascencia-Villa, G., Ramírez, O. T., Palomares, L.A. y Basiuk, V. A. 2008. Scanning Tunneling Microscopy of VP6 Viral Protein Self-Assembly into Nanotubes and Nanospheres. J. Scann. Probe. Microsc. 3, 25-3I.

Samson, J., Alessandro Varotto, Patrick C. Nahirney, Alfredo Toschi, Irene Piscopo, y Charles Michael Drain. 2009. Fabrication of Metal Nanoparticles Using Toroidal Plasmid DNA as a Sacrificial Mold. ACS Nano. 3 (2), 339-344.

Seeman N. C. 2003. DNA in a material world. Nature. 42I,427-43I.

Tseng, R.J.,Tsai, C., Ma, L., Ouyang,J., Ozkan, C., S., y Yang Y. 2006. Digital memory device based on tobaco mosaic virus conjugated with nanoparticles. Nature nanotechnology. I, 72-77.

Yoo, P..., Nam, K.T., Qi, J., Lee, S.-K., Park, J., Belcher,A.M., Hammond, P.T. 2006. Spontaneous assembly of viruses on multilayered polymer surfaces. Nature Materials. 5 (3), 234-240.

Zhang S. 2005. Designing novel materials and molecular machines, eJOURNAL USA, Economic Perspectives. 22-26.

Zhang S. 2003. Fabrication of novel biomaterials through molecular self-assembly. Nature Biotechnology. 21, II7I-II 78.

Zhao X. y Zhang S. 2006. Molecular designer selfassembling peptides. Chem. Soc. Rev. 35, II05-III0. 